Pedagogía y Saberes $n .^{\circ} 55$ Universidad Pedagógica Nacional

Facultad de Educación. 2021. pp. 11-23

\title{
Paulo Freire. Los años del exilio en Chile
}

Paulo Freire: Exile Years in Chile

Paulo Freire: os anos de exilio no Chile

Marcela Gajardo Jiménez*

Para citar este artículo

Gajardo Jiménez, M. (2021). Paulo Freire. Los años del exilio en Chile. Pedagogía y Saberes, (55). https://doi. org/10.17227/pys.num55-12407

* Socióloga de la Educación. Realizó sus estudios de grado en la Universidad Católica de Chile y de posgrado en la Universidad de Essex, Inglaterra. Cofundadora y exdirectora del Proyecto Regional de Educación América Latina (Preal). Actualmente se desempeña como investigadora sénior bajo el amparo institucional de Flacso-Chile donde coordina una plataforma digital de desarrollo educativo (www.preal.online). Correo: marcelagajardoj@gmail.com 


\section{Resumen}

Este artículo se propone aportar nuevos antecedentes, empíricos y conceptuales, sobre la teoría y la práctica de Paulo Freire en Chile. Se trata de una reflexión a partir de una investigación documental sobre los años que Freire vivió exiliado en Chile. Basada en la mejor evidencia disponible, argumentaré que la relevancia y trascendencia que adquirieron las ideas filosóficas y el método pedagógico de Paulo Freire, tanto en América Latina como en su proyección global, se deben, por una parte, a su inserción en contextos que favorecieron su adaptación a diversas situaciones sociales, incidiendo positivamente en una renovación de políticas y prácticas para mejorar la pertinencia y relevancia de los programas de alfabetización y educación de adultos; por otra, a la renovación de metodologías pedagógicas para mejorar la calidad, equidad y efectividad de los procesos de enseñanza y aprendizaje. Hallazgos y conclusiones están enteramente basados en investigaciones históricas y testimonios que dan cuenta del significado que, los años en Chile, tuvieron en el ideario y prácticas de este educador, ahora universal.

Palabras clave

educación de adultos; métodos de alfabetización; educación alternativa; investigación y desarrollo

\section{Abstract}

This article aims to provide new empirical and conceptual background on the theory and practice of Paulo Freire in Chile. The reflection is based on a documentary investigation on the years that Freire lived in exile in Chile. Based on the best available evidence, I will argue that the relevance and significance that the philosophical ideas and pedagogical method of Paulo Freire acquired, both in Latin America and in its global projection, are due, on one hand, to their insertion in contexts that favored its adaptation to various social situations, positively influencing a renewal of policies and practices to improve the relevance and relevance of literacy and adult education programs; on the other, to the renewal of pedagogical methodologies to improve the quality, equity, and effectiveness of the teaching and learning processes. Findings and conclusions are entirely based on historical research and testimonies that account for the significance that the years in Chile had on the ideology and practices of this universal educator.

\section{Keywords}

adult education; literacy methods; alternative education; Investigation and development

\section{Resumo}

Este artigo tem como objetivo fornecer novos fundamentos empíricos e conceituais sobre a teoria e a prática de Paulo Freire no Chile. É uma reflexão a partir de uma investigação documental sobre os anos que Freire viveu exilado no Chile. Com base nas melhores evidências disponíveis, argumentamos que a relevância e o significado que as ideias filosóficas e o método pedagógico de Paulo Freire adquiriram, tanto na América Latina quanto em sua projeção global, se devem, por um lado, à sua inserção em contextos que favoreceram sua adaptação às diversas situações sociais, influenciando positivamente na renovação de políticas e práticas para melhorar a relevância e relevância dos programas de alfabetização e educação de adultos; de outro, à renovação das metodologias pedagógicas para melhorar a qualidade, a equidade e a eficácia dos processos de ensino e aprendizagem. As descobertas e conclusões são inteiramente baseadas em pesquisas históricas e testemunhos que dão conta do significado que os anos no Chile tiveram na ideologia e nas práticas deste educador agora universal.

\section{Palavras-chave}

educação de adultos; métodos de alfabetização; educação alternativa, pesquisa e desenvolvimento 


\section{Introducción}

A mediados de los años sesenta, Paulo Freire (19211997) convulsionó al mundo de la educación de adultos y remeció las bases de la pedagogía tradicional; también las de la entonces incipiente investigación social aplicada a la educación y la enseñanza. Más tarde, y hasta su muerte a los 75 años, defendió la idea de que toda educación, para ser válida, debe ir precedida no solo de una reflexión sobre el hombre, sino de un análisis de la realidad al que se enfrenta quien se quiere educar.

Filósofo y abogado, Freire acuñó el concepto de concientización, con el que explica un proyecto teórico y metodológico para alfabetizar y educar adultos en el que el diálogo, la participación, la aproximación crítica a la realidad y la producción de conocimientos -a partir de esta- son ejes centrales en los procesos de la enseñanza y el aprendizaje. El concepto está indisolublemente ligado a los movimientos de educación y cultura popular que, en los años sesenta, impulsaban la movilización y organización de vastos sectores marginales de la ciudad y el campo, para reivindicar, frente al Estado, el acceso a bienes económicos, servicios sociales y una participación política en diversos grados y niveles.

Inicialmente vinculados a políticas de alfabetización de adultos, con el correr del tiempo estos programas pasaron a ser una entre varias alternativas de expresión de una búsqueda pedagógica que se proponía vincular la educación de los sectores populares, con otros más amplios de transformación política y social. Se elegían grupos, clases o fracciones de clase tradicionalmente excluidos de los beneficios de la educación y la cultura, grupos sociales que vivían en condiciones de marginalidad y pobreza. En concordancia con teorías en boga en aquellos años, dicha situación se atribuía a la existencia de una sociedad dual donde coexistían sectores rezagados con otros más modernos y desarrollados. Lograr la participación e integración de los grupos marginados a la vida nacional requería de un cambio de valores y de comportamientos. De la superación de lo que Freire llamaba una conciencia mágica o conciencia oprimida, albergue de mitos y creencias que mantenían a los sectores populares como una categoría social pasiva y carente. Se requería, según diagnósticos de la época, de una educación que posibilitara transitar de un estado de conciencia ingenua a uno de conciencia crítica.

Las ideas pedagógicas de Paulo Freire y su método de alfabetización se difundieron ampliamente, primero en Brasil (1961-1964), más tarde en Chile (1965-1973) y, después a otros países latinoamericanos; luego a Estados Unidos, Europa y África. Freire adquirió notoriedad universal al transformarse en uno de los pensadores más conocidos, creativos e influyentes de América Latina. Su paso por las más prestigiosas universidades del mundo revolucionó las cátedras, pero su actividad académica nunca interfirió con su práctica de educador comprometido con la causa de una educación puesta al servicio de sociedades más justas, equitativas y solidarias.

Hasta aquí la historia de este educador latinoamericano es conocida y está ampliamente documentada: ¿Qué hay de nuevo, entonces, para contar sobre el origen y evolución de la pedagogía de Paulo Freire?; ¿cuál sería, después de tanto tiempo, la mejor forma de contarlo?

Esta nueva publicación sobre la pedagogía de Paulo Freire se propone entregar algunas claves sobre el origen y evolución de su método acelerado de alfabetización de adultos y aportar nuevos antecedentes, empíricos y conceptuales, sobre el desarrollo de sus teorías pedagógicas a partir de los años que vivió exiliado en Chile, entre 1964 y 1969. Específicamente se persigue:

a. Reconstruir y contextualizar el pensamiento pedagógico de Freire, a partir de sus primeros escritos en Chile y su práctica con educadores chilenos e intelectuales brasileños avecindados en el país, después del golpe cívico-militar en Brasil.

b. Describir los principales rasgos de su metodología pedagógica, así como sus supuestos teóricos y metodológicos.

c. Examinar la contribución de esta pedagogía al desarrollo de políticas basadas en una distribución más equitativa del conocimiento, la información y las oportunidades educativas.

El objeto de análisis es la teoría y la práctica de Paulo Freire en Chile, la aplicación de su método de alfabetización y su estrategia metodológica para determinar contenidos de enseñanza en programas y políticas de posalfabetización asociadas al proceso de reforma agraria. El análisis es de tipo documental y se sustenta en ensayos, informes y documentos preparados en el marco de las actividades del Instituto de Capacitación e Investigación en Reforma Agraria (Icira), información de fuentes secundarias e información proveniente de entrevistas realizadas, por terceros, a profesionales chilenos que colaboraron directamente con Freire durante su permanencia en Chile. Las preguntas en busca de respuestas son las siguientes:

a. ¿Qué propuestas educativas, teóricas y metodológicas, desarrolló Paulo Freire en Chile? 
b. ¿En qué contexto institucional las implementó?

c. ¿Cómo se divulgaron estas ideas pedagógicas hacia otros países de América Latina y el mundo?

d. ¿Lograron estas ideas influir el diseño de políticas educativas para mejorar la educación y los aprendizajes?

El texto se ha dividido en tres partes. La primera da cuenta de los orígenes e ideas que influyeron la teoría y la práctica de Paulo Freire, desde el momento en que empieza a experimentar con su método de alfabetización de adultos en Brasil, hasta que se ve forzado a dejar su país para vivir en el exilio. El segundo está referido a dicha actividad en Chile, su adaptación a la realidad de la época y su adopción como parte de las políticas públicas de alfabetización y educación de adultos, y programas nacionales de capacitación para la reforma agraria. En tercer lugar, se examina el impacto de la pedagogía e ideas pedagógicas de Paulo Freire sobre el desarrollo de nuevas teorías y nuevas prácticas, dentro y fuera de América Latina. Por último, se presenta una relación bibliográfica de documentos redactados por Paulo Freire y algunos otros que hablan sobre él.

\section{De la filosofía a la pedagogía (1950-1960)}

Paulo Freire llegó a Chile a los 43 años, precedido por su experiencia profesional en el Servicio Social de la Industria (SESI), su práctica académica en lo que hoy es la Universidad de Pernambuco y las lecciones aprendidas en la ejecución de un microproyecto de alfabetización de adultos, en la localidad de Angicos, aplicando experimentalmente metodologías pedagógicas para enseñar a leer y escribir a adultos analfabetos, en solo 40 horas cronológicas, con un método de su autoría. Este periodo culminó con su nombramiento como coordinador general del Programa Nacional de Alfabetización bajo la administración del gobierno de Joao Goulart (1959-1964), destituido por un golpe militar que puso fin a las formas de gobierno democrático y acabó, también, con muchas de las innovaciones educativas que, desde el gobierno y las organizaciones de la sociedad civil, se venían desarrollando en diversos estados de Brasil. Para muchos, significó el exilio, para otros, equivalió a retrotraerse al interior de sus organizaciones y, más tarde, recomenzar un trabajo de educación popular a partir de las comunidades eclesiales de base y movimientos sociales vinculados a la acción pastoral de las iglesias.
En Chile, y a partir de escritos y conferencias públicas, Freire introdujo el concepto de la concientización, un neologismo para el cuál no existe una definición precisa. Desde un punto de vista pedagógico, la noción remite a un aprendizaje orientado hacia la percepción de realidades económicas, políticas y sociales como requisito indispensable de la acción política y social; desde una perspectiva filosófica, vincula ciencia y existencia, hace consciente la realidad y las contradicciones del mundo humano. Remite, además, a una epistemología donde, de manera ecléctica, se mezclan muchas escuelas de pensamiento filosóficas, sociológicas, psicológicas y pedagógicas.

Noción olvidada en la sociología contemporánea pero central en las ideas pedagógicas de Freire, el término concientización empezó a ser regionalmente conocido como un concepto creado por un equipo de profesores del Instituto Superior de Estudios Brasileros (ISEB) hacia 1964. Freire añade luces al origen del concepto cuando, participando en un seminario internacional en Roma, señaló que al oírlo de boca del filósofo Álvaro Viera Pinto y el profesor Guerreiro Ramos había entendido que, aplicado a la educación, aludía a su potencial creador y crítico (Freire, 1972). Concepto, método e ideas pedagógicas son, hoy, universalmente conocidas a través de publicaciones traducidas a los más diversos idiomas. Entre ellas, La educación como práctica de la libertad (1965) y Pedagogía del oprimido (1970).

En La educación como práctica de la libertad (1965), y según sus propias palabras, Freire entrega una revisión ampliada de la tesis que defendió para obtener una cátedra en la Universidad de Pernambuco. A ella incorpora lecciones aprendidas con la aplicación masiva de su método de alfabetización y, paralelamente, entrega un pormenorizado registro del camino recorrido con el diseño y aplicación de lo que en Brasil se conoció, ampliamente, como el método Paulo Freire, mucho antes de su adaptación a la realidad chilena donde se le utilizó en campañas y proyectos de alfabetización y programas de desarrollo rural y capacitación campesina.

En Pedagogía del oprimido (1970), en cambio, Freire avanzó en la elaboración de una teoría pedagógica general a partir del trabajo realizado con técnicos y campesinos chilenos en el marco de procesos amplios de transformación agraria. Siempre desde la óptica de la educación y la enseñanza, y mediante el uso de categorías de análisis marxistas, reinterpretó su pedagogía a la luz de nuevos referentes teóricos e inició la tarea de formular una teoría de la acción cultural basada en conceptos de dialéctica y libertad, como ejes de un estilo renovado de investigación, 
acción pedagógica y prácticas políticas que, por años, inspiró a los movimientos de educación y cultura popular dentro y fuera de América Latina.

Actualmente existe evidencia empírica suficiente como para argumentar que, mediante las intervenciones realizadas en Chile, Freire y sus colaboradores —pedagogos, sociólogos, psicólogos, lingüistas, filósofos y planificadores del desarrollo- introdujeron nuevos elementos en la manera de pensar y hacer educación, en general, y educación de adultos, en particular. De hecho, Freire fue uno de los primeros que, en América Latina, definió contenidos de enseñanza en función de las condiciones de vida y de trabajo de los adultos, su entorno y realidad cultural. También fue uno de los primeros en reconocer que el analfabetismo es un problema social y que los mal llamados analfabetos, por no manejar los códigos básicos de la lectura y la escritura, son poseedores de un saber y una cultura que pueden y deben ser consideradas como punto de partida en los procesos de enseñanza y la organización de los aprendizajes.

Durante los años en que Freire formó parte de una comunidad intelectual de Chile, introdujo la investigación social como etapa previa a la elaboración de contenidos educativos y, mediante el uso de enfoques y técnicas participativas de indagación, logró demostrar, a profesionales de la agronomía y de la educación, que podían ser educadores y educandos de los adultos con los que trabajaban y, a la vez, producir conocimientos a partir de las realidades que pretendían transformar. Propuso una didáctica para el educando adulto que, siendo de raíz sociológica, tenía amplia justificación en la psicología social y, puesta en la perspectiva del extensionismo rural y agrícola, introducía conceptos y técnicas de comunicación que permitían acercar a agrónomos y extensionistas agrícolas a la cultura campesina y desarrollar una mejor comprensión sobre sus formas de producir y de cultivar la tierra.

Algunos estudios al respecto aportan evidencia empírica sobre el contexto en que surgieron y se desarrollaron las ideas que sustentan este método pedagógico y las bases, epistemológicas, filosóficas y metodológicas, sobre las que se construyó esta teoría pedagógica. Una teoría que, más que de supuestos $a$ priori o de marcos teóricos existentes, emergía de la práctica con el propósito de identificar procesos sociales básicos a través de conceptos, hipótesis y proposiciones que aportaran a la explicación del fenómeno estudiado.

En los importantes esfuerzos por estudiar la trayectoria intelectual y política de Paulo Freire en Chile, existen vacíos de información sobre los contextos institucionales y políticos en los que este pensador desarrollaba sus teorías pedagógicas. Otros estudios sobre su trayectoria en Brasil, sin embargo, evidencian que, en el pensamiento político y pedagógico de Freire, pueden distinguirse tres grandes etapas.

La primera, desde mediados de los años cincuenta a mediados de los sesenta, coincide con el periodo en que formuló y aplicó su método de alfabetización acelerada de adultos en Brasil, mejor conocido como método Paulo Freire o método de concientización, difundido más tarde en Chile como método psicosocial de alfabetización de adultos (Freire, 1968).

La segunda transcurre entre noviembre de 1964, fecha de su llegada a Chile, y finales de 1968. Coincide con el tiempo del exilio de un número importante de políticos e intelectuales brasileños en Chile donde Freire pasó a desempeñarse como consultor del Gobierno nacional en la sede del Instituto de Desarrollo Agropecuario (Indap) primero y, poco más tarde, como consultor de la Unesco en el Instituto de Capacitación e Investigación para la Reforma Agraria (Icira), un proyecto de cooperación entre el Gobierno de Chile, el Programa de Naciones Unidas para el Desarrollo y la FAO, creado en 1964 e intervenido después del 11 de septiembre de 1973.

Una tercera etapa se inicia a comienzos de 1969 cuando nuevamente, por razones políticas, Freire ve interrumpido su trabajo en Chile y truncados sus esfuerzos por construir una teoría que resumía gran parte de su concepción educativa y lo que, en esa época, definiera como una concepción bancaria de la educación, contraponiéndola a lo que promovía como una concepción liberadora, crítica y problematizadora (Freire, 1972 Concepción en Sobre la Acción Cultural).

La evidencia disponible indica que la influencia de estas ideas sobre la formulación y ejecución de políticas de alfabetización y educación de adultos fue enorme, dentro y fuera de América Latina. Gran parte de ella ocurrió a través de las acciones de grupos y redes de educadores cristianos comprometidos con el cambio social y organizaciones de iglesia que iniciaban un proceso de renovación institucional bajo el marco de lo que, en los años sesenta y setenta, se conoció como teología de la liberación. Estos actores adoptaron el método de concientización y divulgaron las ideas pedagógicas de Freire que prendieron rápidamente entre organizaciones y movimientos de educación de base y entre sociólogos y politólogos ocupados en programas de desarrollo rural y transformaciones agrarias.

Divulgados mediante charlas y publicaciones como informes, manuales, cartillas y materiales pedagógicos preparados y utilizados en actividades de 
formación de monitores y alfabetizadores o en actividades de investigación y capacitación campesina-. estos materiales fueron profusamente utilizados por entidades del sector público y comunidades eclesiales de base para promover debates informados sobre educación y control social por parte de grupos e instituciones cristianas ocupadas en proyectos de educación de base y educación popular. Una de estas antologías que, paradójicamente, antecedió la publicación de Pedagogía del oprimido y Sobre la acción cultural fue publicada por ISAL, en 1968, bajo el título de Cristianismo y sociedad, texto que reunió una serie de ensayos escritos por Paulo Freire y su equipo en el marco de actividades de investigación y capacitación de Icira, así como ponencias y ensayos preparados para seminarios en Chile y otros países de América Latina, varios de ellos incluidos en compendios bibliográficos que han intentado reconstruir su trayectoria intelectual durante los años de su exilio en Chile ${ }^{1}$. Posteriormente, estos ensayos - algunos de los cuales también formaron parte del núcleo de Pedagogía del oprimidofueron reorganizados y publicados en la dirección que originalmente les dio su autor siguiendo la lógica de las audiencias a las que se dirigían los mensajes².

1 ISAL (Freire, 1968); Inodep (1972); Torres (1979); Gadotti et al (1996)

2 Tres módulos temáticos dentro de Sobre la acción cultural sirvieron para reorganizar estas ideas. El primer módulo, bajo el título "La educación como una dimensión de la Acción Cultural" (pp. 19-51) incluyó "La concepción bancaria y la concepción problematizadora de la educación"; "La alfabetización de adultos"; "La práctica del método psicosocial"; "Los campesinos también pueden ser autores de sus propios textos de lectura". Un segundo módulo, organizado bajo el título "El movimiento dialéctico de la acción cultural" (pp. 52-79) recogió los textos "Investigación de la temática generadora" (pp. 51-66); “A propósito del tema generador y del Universo temático (pp. 66-77). Un tercer apartado, "Acción cultural y cambio" (pp. 79-110), incluyó los textos más directamente relacionados con prácticas educativas realizadas en el marco del proceso chileno de la reforma agraria: "Acción cultural y reforma agraria" (pp. 79-88); "El rol del trabajador social en el proceso de cambio" (pp. 88-101); "El compromiso del profesional con la sociedad" (pp. 102-106). La versión digital de Sobre la acción cultural en su tercera edición (1972) se encuentra disponible en línea en academia.edu. En 1979, algunos de estos textos y otros ensayos preparados para conferencias y seminarios en Estados Unidos y Europa fueron revisados y editados por el autor, y publicados bajo el título de Acao cultural para a liberdade e outros escritos (Freire, 1979), Sao Paulo, Brasil.
A finales de 1968, el Gobierno de Chile decidió no renovar el contrato de consultoría internacional que Freire mantenía con la Unesco, bajo acusaciones de provocar, en un contexto político cada vez más radicalizado, la politización de algunos grupos sociales, especialmente de organizaciones campesinas y redes de pobladores urbano-marginales. Puesto en la disyuntiva de permanecer en Chile o dejar el país, decidió aceptar una posición como profesor visitante en la Universidad de Harvard. La invitación, cursada por el Center for Studies in Development and Social Change, era para trabajar y poner en debate la teoría de la acción cultural esbozada en Pedagogía del oprimido, libro que a la fecha ya circulaba dentro y fuera de Estados Unidos.

Freire ejerció como académico en Harvard por un periodo de diez meses, a partir de abril de 1969. Ofreció varias conferencias y publicó dos textos en inglés que sirvieron de base para extrapolar su teoría del método de la concientización a los procesos de transformación cultural y a otros campos disciplinarios, especialmente los del mundo de la teología y la política (Freire, 1972).

A comienzos de 1970 dejó Estados Unidos y se trasladó a Europa como especialista en educación del Consejo Mundial de Iglesias, con sede en Ginebra, donde permaneció hasta finales de 1979. En calidad de consultor, asesoró a organizaciones y grupos ecuménicos y presidió varias asociaciones internacionales dedicadas a promover transformaciones sociales y culturales en los más diversos contextos y situaciones sociales. Inauguró su nueva posición, colaborando en la organización de un seminario internacional, donde llevó la voz de América Latina a través de su propia participación y la de un pequeño grupo de profesionales liderados por el exministro de Educación de Brasil, Paulo de Tarso Santos ${ }^{3}$.

A partir de entonces, Freire volcó sus actividades hacia Europa, de una parte, y hacia África, de otra. Trabajó apoyando a los gobiernos de Angola, Guinea-Bissau, Cabo Verde, Mozambique, Santo Tome e Príncipe, y asesoró varias de las campañas de alfabetización y desarrollo educativo en estos países. Regresó a Chile en dos oportunidades. En 1972, para reunirse con educadores chilenos y debatir sobre la orientación de los procesos de transformación educativa y las políticas de alfabetización y educación de adultos del gobierno de la Unidad Popular. En 1991, para conocer la opinión y actitud del mundo cristiano frente a los

3 Seeing Education Whole (1971), convocado por el Consejo Mundial de Iglesias y realizado en Bergen Am See, Holanda, 
cambios sociales y políticos de la época, intercambió ideas con teólogos chilenos sobre la misión educativa de las iglesias en América Latina. ${ }^{4}$

\section{De la pedagogía a la política (1970-1980)}

En Chile, la crítica de Freire a la educación y la enseñanza fue, desde un comienzo, profunda a las prácticas pedagógicas centradas en el profesor, desvinculadas de la realidad del entorno y las necesidades de aprendizaje de los alumnos.

En su propuesta alfabetizadora, la materia prima del proceso educativo la proporcionaba la realidad inmediata y los problemas que cotidianamente vivían los educandos. Realidades y problemas sociales, económicos y políticos constituían la base a partir de la cual se construía el proceso educativo. La sala de clases y el entorno escolar se remplazaban por una unidad flexible de organización del trabajo pedagógico. Eran los denominados círculos de cultura formados por pequeños grupos que funcionaban en los lugares de trabajo o de residencia. A partir de ellos se redefinía la relación pedagógica y el papel del profesor quien, en el interior del círculo, debía limitarse a coordinar las actividades de enseñanza, facilitar los aprendizajes y promover el diálogo y la reflexión a partir de temáticas y problemas de interés común. En tanto estrategia político-pedagógica, cuyo fin era promover aprendizajes sociales, se privilegiaba la problematización por sobre la memorización y se promovía la búsqueda de una síntesis entre culturas por sobre la imposición de una cultura sobre otra. Trabajando estos principios, derivados de su práctica educativa con adultos analfabetos en condiciones de marginalidad y pobreza, Freire estableció un punto de partida para la elaboración de una teoría pedagógica a la que siempre se refirió como una teoría de la acción cultural (Freire, 1972).

Paulo Freire nunca terminó de desarrollar completamente esta teoría en Chile. Interrumpió su desarrollo al momento de dejar el país y volvió a retomarla

4 De esta época son el conjunto de entrevistas que Freire sostuvo entre los años 1969 y 1975 para revistas como Víspera de Uruguay, Cuadernos de Pedagogía de España y RISK publicada en Ginebra (Suiza). Específicamente referida a sus años de trabajo en Chile es la entrevista que originalmente publicó Cuadernos de Pedagogía de la Universidad Católica de Chile, a raíz de la visita a fines de 1972, y la segunda, publicada en abril de 1973 por IDAC, en Ginebra, donde, cuestionado sobre la creciente aceptación de su pensamiento en Estados Unidos, Europa y América Latina, Freire lamenta que fuera, precisamente en América Latina, donde se presentaban las críticas más severas a sus ideas, práctica y pensamiento. solamente en dos oportunidades: con ocasión de su estadía de diez meses como profesor invitado en la Universidad de Harvard (1969-1970) y más tarde, hacia finales de los años setenta, cuando colaboró en la formulación de políticas de desarrollo educativo conjuntamente con organizaciones europeas que trabajaban asociadas a gobiernos de países de África poscolonial en asociación con académicos y profesionales del Instituto de Acao Cultural (Idac) ${ }^{5}$.

Evidencia pasada y reciente sobre la teoría y la práctica de Paulo Freire en Chile aporta claves importantes sobre el contexto en el que surgieron y se desarrollaron estas ideas pedagógicas. De hecho, a fines de 1964 cuando Paulo Freire se estableció en Chile, ya se encontraban en marcha dos importantes procesos de transformación económica y social: la reforma agraria chilena y la denominada Reforma Integral de la Educación que incluía cambios en el currículo escolar y en la orientación y contenidos de los programas de alfabetización y educación de adultos. Acogido en el exilio por el Gobierno demócrata cristiano de la época (1964-1970), Freire se integró tempranamente al equipo de profesionales del Instituto de Desarrollo Agropecuario (Indap), asesoraba sus planes y programas de alfabetización campesina, y apoyaba programas sectoriales de capacitación ejecutados en convenio con el Ministerio de Educación. Al mismo tiempo, iniciaba un proceso de adaptación a la cultura y el contexto de la sociedad chilena ${ }^{6}$.

En el Ministerio de Educación asesoraba a la Jefatura de Planes Extraordinarios de Educación de Adultos, del Ministerio de Educación, en la preparación de un manual nacional de alfabetización con base en la adaptación del método de la concientización ${ }^{7}$. Con estos materiales se elaboraban, además, cartillas y textos para apoyar actividades de alfabetización campesina en asociación con la Corporación de la Reforma Agraria (CORA) y materiales preparados para capacitar a pequeños propietarios y campesinos minifundistas en asociación con técnicos y extensionistas del Indap. La meta era reducir, primero, y eliminar,

5 Al respecto ver Freire (1985).

6 Ver facsímil de Carta as Amigas de Paulo Freire en Gajardo (2019), y para un análisis del contenido de los manuales de alfabetización y los gráficos que acompañaban las palabras generadoras ver Freire (1972).

7 Manual del método psico-social para la enseñanza de adultos, conocido también como La raíz y la espiga, utilizado en la campaña de alfabetización del año 1965 y Sugerencias para la alfabetización, manual utilizado en programas de alfabetización y en programas nacionales de educación de trabajadores bajo el gobierno de Salvador Allende (1970-1973), respectivamente. 
después, el analfabetismo en el campo ${ }^{8}$ mediante un conjunto de medidas que corrieron en forma paralela con otras transformaciones del sistema escolar para garantizar acceso universal a la educación básica.

En el sector educativo, correspondía a la Jefatura de Planes Extraordinarios de Educación de Adultos liderar los procesos de alfabetización y diseñar programas acelerados de educación básica para adultos con escolaridad incompleta. En todos ellos, se utilizó el método psicosocial para tareas de alfabetización y nivelación educativa en cursos vespertinos que utilizaban centros comunitarios y centrales de capacitación como base institucional de los programas. Se dictaron decretos especiales para el uso pleno y múltiple de los locales escolares y se ampliaron las funciones administrativas del sector. Se elaboraron materiales y se establecieron convenios intersectoriales con el fin de vincular la alfabetización y educación de adultos con los programas de transformación agraria, sindicalización campesina y otras actividades de promoción popular.

Dentro de las políticas de educación formal correspondió a los Centros de Educación Básica y Media Comunitaria la tarea de facilitar el acceso o reinserción de los adultos al sistema educacional. A 1968, estadísticas oficiales registraban dos mil centros de educación básica y comunitaria funcionando en el país en locales sindicales, asentamientos y comités campesinos, centros de capacitación, juntas vecinales y centros de madres, entre otras organizaciones de base. Un número no menor de diez mil profesores se capacitaron en el uso del método psicosocial, a través de los manuales especialmente preparados sobre el método?.

En cuanto a los procesos de cambio agrario, las actividades de Paulo Freire se desarrollaron mayoritariamente en el marco de las políticas y programas educativos asociados a los procesos de transformación

8 La meta durante el gobierno de Eduardo Frei Montalva fue reducir el analfabetismo de un $16,4 \%$ a un $5 \%$, mientras que en el gobierno de Salvador Allende la meta consistía en la erradicación del analfabetismo. En ambas administraciones, las políticas de alfabetización y programas educativos para adultos se diseñaron y ejecutaron bajo la coordinación de la cartera de educación articulada con las instituciones a cargo de la ejecución de las políticas de reforma agraria y sindicalización campesina.

9 Los esfuerzos en esta dirección le valieron al Gobierno de Chile un reconocimiento internacional. A mediados de 1967, la Unesco le otorgó la Medalla Premio Mohammed Reza Pahlevi a la Jefatura de Planes Extraordinarios de Educación de Adultos de Chile, como reconocimiento al esfuerzo sistemático para reducir rápidamente la tasa de analfabetismo del país y para integrar los programas de alfabetización a los objetivos del desarrollo nacional (Mineduc, 1966b) agraria y, muy especialmente, en las actividades de capacitación e investigación que se desarrollaban en el Indap, primero, y en el Icira, después. El impacto de las actividades de esta institución sobre los procesos de cambio agrario forma parte de épocas pasadas. También las investigaciones socioeconómicas que allí se llevaron a cabo y la formación de recursos humanos para un proceso profundo y complejo que comprometió a toda una generación de economistas, sociólogos, agrónomos, extensionistas y educadores, entre los muchos profesionales vinculados al desarrollo rural y la reforma agraria.

Freire compartió en el Icira junto a otros exiliados brasileros que incluían a Paulo de Tarso Santos, exministro de Educación y responsable del Departamento de Capacitación en Icira, y Almino Affonso, exministro del Trabajo que, en el Icira, lideraba estudios sobre el movimiento campesino chileno. También con economistas como Fernando H. Cardoso que, desde la Cepal, trabajaba su teoría de la dependencia y con otros intelectuales y pensadores de fenómenos sociales y culturales como, por ejemplo, Darcy Ribeiro que, en apasionados debates, solía decir que las escuelas latinoamericanas eran una calamidad y que la cultura y las universidades no eran nada sino un simple reflejo del subdesarrollo regional (Cardoso y Faletto, 1969; Freire, 1992) ${ }^{10}$.

Adscrito a Icira como experto de la Unesco (19671969), las responsabilidades de Freire incluían la asesoría pedagógica a instituciones públicas como la CORA y el Indap, colaborando en la adaptación de su método de alfabetización para ser utilizado en la Campaña Nacional de Alfabetización. Oficiaba como profesor invitado en universidades católicas y como parte de sus presentaciones y conferencias públicas preparaba textos y materiales para la formación de profesionales ocupados en el diseño e implementación de programas de desarrollo rural y cambio educativo, actividades de extensión universitaria, cursos de capacitación campesina y asesoría técnica a entidades nacionales y extranjeras.

Trataba además, en este periodo, de aplicar una estrategia metodológica de investigación en la acción para derivar de allí temas generadores que, a su vez, servirían para el desarrollo de actividades de posalfabetización y capacitación campesina y colaboraba

10 En su libro autobiográfico, Pedagogía de la esperanza: un reencuentro con la pedagogía del oprimido, publicado en 1992 Freire describe su paso por Icira como uno de los momentos más productivos de su experiencia en el exilio. En parte lo atribuye al clima intelectual que se respiraba en dicho organismo y al hecho de que allí reencontró a pares de su generación, entre muchos de los brasileños que, en esos años, se desempeñaron en la institución. 
en la formación de técnicos y profesionales de otros países de América del Sur, como Perú y Colombia, que solicitaban asistencia técnica al Icira y otras organizaciones del sistema de Naciones Unidas para formular o ejecutar políticas y programas de cambio agrario ${ }^{11}$.

Varias publicaciones recogen los resultados de este esfuerzo ${ }^{12}$. Por una parte, escritos dispersos preparados y utilizados por Freire en el marco de actividades del Ministerio de Educación con sugerencias para la adaptación y aplicación del método de alfabetización a la realidad chilena de la época y para formar alfabetizadores para la Campaña Nacional de Alfabetización del Ministerio de Educación de Chile. Los otros son textos y materiales producidos en el marco de las actividades de instituciones que lideraban procesos de transformación agraria para divulgar la teoría y la práctica del método entre sus técnicos y profesionales ${ }^{13}$.

Fue en este contexto general donde Paulo Freire empezó a desarrollar su teoría pedagógica mediante una combinación de conceptos referidos a la política y a la acción cultural que, más tarde, plasmó en Pedagogía del oprimido. A lo largo de sus cuatro capítulos, Freire reflexiona, desde una perspectiva filosófica, sobre el origen de su práctica con el método de alfa-

11 Mineduc (1966a); Ferreira y Fiori (1971) y Freire (1972).

12 El primero, es la colección de ensayos publicados bajo el título de Sobre la acción cultural (www.academia.edu). La segunda publicación, organizada por María Edy Ferreira y José Luiz iori, fue divulgada bajo el título Investigación de la temática cultural de los campesinos de "El Recurso", un informe preliminar. En este se registran las distintas etapas del estudio, los antecedentes históricos del asentamiento, el registro de las observaciones iniciales en la comunidad y los antecedentes que sirvieron de base para la construcción de códigos y gráficos utilizados en los círculos de investigación y cultura con los campesinos beneficiarios de la reforma agraria, minifundistas y pequeños propietarios. Paulo Freire escribió dos textos respecto de estas etapas. Uno titulado Investigación de la temática generadora y, el segundo, A propósito del tema generador y el universo temático (1968). Parte de ellos fueron incluidos en el segundo capítulo de Pedagogía del oprimido, por un lado, y en la colección de ensayos incluidos en Sobre la acción cultural, por otro. En textos y materiales producidos en el marco de estas etapas, algunos de ellos inéditos y otros publicados de manera dispersa, sin hilos conductores y sin haberse recopilado en una única publicación, se encuentra mucho de lo que Freire produjo durante sus años de exilio político en Chile y que, más tarde, proyectó hacia Europa y algunos países africanos como una teoría de la acción cultural.

13 Un importante número de estos informes se encuentra digitalizado en el Fondo José Miguel Arguedas del Centro de Patrimonio Inmaterial de la Biblioteca Nacional de Chile. Entre estos documentos existen textos escritos originalmente por Paulo Freire, algunos de ellos en asociación con algunos de sus colaboradores cercanos. Siete de ellos fueron seleccionados para este escrito y están disponibles en línea como anexos del e-book Paulo Freire. Crónica de sus años en Chile (www.academia.edu). betización y concientización, percibida como bastante limitada, a la alfabetización como práctica política e instrumento de formación ciudadana. Desde el primer capítulo, introduce los conceptos básicos de la denominada concepción bancaria y problematizadora de la educación; enfatiza el diálogo como esencia de la educación en calidad de práctica de la libertad y explora la investigación de las temáticas culturales para definir contenidos programáticos en la educación de los adultos. De otra parte, en el capítulo tercero, se refiere a los resultados experimentales de una metodología de investigación de universos temáticos y temas generadores como prácticas colectivas de conocimiento y acción.

Las contrapartes nacionales del equipo de Paulo Freire en Icira y otros organismos eran técnicos, especialmente agrónomos y extensionistas a cargo de la ejecución de programas y políticas de cambio agrario. Por eso, la mayoría de los ensayos referidos a la extensión agrícola que se producían en el campo de la capacitación tenían por propósito sensibilizar estos profesionales sobre la importancia de promover un análisis sobre la relación entre técnica, modernización y humanismo, así como entre modernización, desarrollo y aprendizaje. En ensayos escritos para estos actores, contenidos en su libro ¿Extensión o comunicación?, Freire partía del análisis semántico del término extensión, deteniéndose en consideraciones a propósito de la invasión cultural, discutiendo la reforma agraria y el cambio, oponiendo la comunicación a la extensión y refiriéndose a la educación como una situación gnoseológica en cuya práctica la denominada asistencia técnica tenía otras dimensiones. Por último, mostraba, con ejemplos de la práctica y palabras campesinas, cómo la labor educativa de los agrónomos, al igual que la de los maestros, debía priorizar la comunicación si con ella se perseguía llegar a hombres concretos, históricamente situados (Freire, 1972).

En el campo de la investigación, en cambio, las contrapartes de Freire eran equipos interdisciplinarios de sociólogos y politólogos ocupados en el análisis de políticas y en el desarrollo de estudios sobre la dinámica de la reforma agraria, en general, y sobre el movimiento campesino chileno, en particular. Los escritos de Freire, en este sentido, se ubicaban en una doble perspectiva. Mientras, por un lado, examinaba el papel que le cabía a los extensionistas en los procesos de reforma agraria y transformación cultural, por el otro, intentaba contribuir a los procesos de transformación social en el agro mediante el diseño de una investigación que combinaba estilos participativos de indagación social con estrategias de acción para el cambio cultural en el campo. 
En este contexto, y con el fin de organizar algunos estudios para determinar contenidos programáticos, Freire ideó un estilo de trabajo a partir de lo que llamaba investigación de universos y temáticas culturales, y coordinó la primera fase del proyecto institucional "Investigación de la temática cultural de los campesinos de 'El Recurso'”. El punto de partida estuvo dado por cambios culturales ocurridos en el marco de la reforma agraria. Su objetivo consistía en aportar antecedentes, empíricos y conceptuales, para diseñar una política de capacitación que posibilitara a los campesinos adquirir ciertos conocimientos y competencias al tiempo que modificaban comportamientos y actitudes heredadas del sistema de inquilinaje, una de las formas más clásicas de dominio en el campo. En las palabras de Freire, se trataba de "estudiar el pensar del pueblo, sus ideales, su temática" (Freire, 1972, pp. 60-61). En otras palabras, de avanzar en una mejor comprensión de la ideología campesina, del modo en que los campesinos, hasta entonces insertos en una estructura agraria tradicional, construían la realidad social. Como proyecto, la experiencia comprendía una etapa de naturaleza sociológica y otra de naturaleza pedagógica. En la etapa sociológica, el esfuerzo se ponía en el levantamiento de situaciones representativas de algunas contradicciones subyacentes a la estructura y procesos agrarios para, previa codificación y construcción de imágenes, decodificarlas posteriormente con los campesinos. La etapa de investigación incluía tres pasos: a) observación y codificación, b) decodificación en círculos de investigación, y por último, c) devolución de resultados con fines de programación ${ }^{14}$.

Por cada conjunto se identificaron situaciones empíricas que reflejaban lo vivido por la comunidad de asentados desde el momento en que los campesinos del lugar reivindicaron su derecho a la propiedad de la tierra y marcharon con banderas y herramientas en el camino principal del fundo, hasta el momento en que se les asignaron las tierras y surgieron los primeros problemas dentro de las formas de producción colectiva del predio asignado. Dado el peso de la escuela en

14 Ferreira y Fiori (1971). En el caso del asentamiento El Recurso, después de un periodo de observación inicial, se procedió a un registro de las características del predio con base en las siguientes variables: a) características del asentamiento, b) número de familias asentadas, c) antecedentes históricos, d) procesos y relaciones de producción predominantes, e) procesos de socialización y formas culturales predominantes. Luego, se procedió a la selección de un conjunto de situaciones, traducidas en imágenes, codificadas en torno de cuatro formas de relación social: a) la relación de los campesinos con la tierra; b) la relación patrón, inquilinos/campesinos; c) relación entre trabajo individual y trabajo colectivo, y por último, d) relaciones culturales referidas al trabajo y el ocio o diversión. la comunidad, la educación y las formas de relación pedagógica fueron graficadas a partir de relaciones entre políticas de capacitación, funciones de la escuela, así como la forma en que padres e hijos podían participar de la gestión de los procesos educativos. Por otra parte, se consideró el aporte de la educación al mejoramiento de la producción, las relaciones educación escolar y educación extraescolar y el papel que cabía a técnicos e instituciones del agro en las actividades de capacitación de los campesinos asentados.

El registro de percepciones campesinas se trabajó en círculos de investigación donde, separadamente, un grupo de hombres y uno de mujeres asentadas, conjuntamente con un facilitador y los miembros del equipo de investigación de Icira, procedieron a decodificar las imágenes que graficaban las situaciones seleccionadas y a grabar íntegramente los discursos campesinos. La etapa de decodificación se entendió como la descripción y análisis de las situaciones detectadas y textualmente registradas por uno o más facilitadores que proporcionaron el discurso campesino. A partir de ello se identificaron temas generadores que se definieron como ideas-fuerza en la percepción campesina y debían servir como insumo para construir el contenido programático de la capacitación.

Luego se procedió a la organización de los datos y se inició el trabajo de análisis del discurso de los campesinos asentados para proceder a traducirlos en contenidos pedagógicos y, desde una perspectiva sociológica, construir una matriz teórica mediante la combinación de tres conceptos: a) la opresión, tal y como se la concebía desde la perspectiva de situaciones de dominio social y político; b) las relaciones de dependencia económica, cultural, política y familiar entre centro y periferia, y c) la cultura de la marginalidad construida con base en teorías sobre la reproducción de valores y creencias impuestas por una cultura dominante sobre una cultura dominada ${ }^{15}$.

Fue a lo largo de este trabajo que Freire pudo constatar que primeras letras, instrucción, conocimientos mínimos, toma de conciencia sobre la realidad más cambio de comportamientos, actitudes y

15 El trabajo de campo en el asentamiento El Recurso se realizó entre octubre y noviembre de 1968. Los registros de las etapas de observación y decodificación de las imágenes utilizadas para identificar el universo cultural y las percepciones de los campesinos asentados sobre la situación en su predio reformado fueron sistematizados y publicados entre 1970 y 1971. La etapa de programación nunca llegó a completarse. Contrariamente a lo que ocurrió en otros países de América Latina, donde se aplicaron con éxito las distintas etapas de la investigación temática y surgieron distintas vertientes investigativas como la investigación en la acción, las investigaciones participativas y la investigación militante. 
aprendizajes sociales, ya no bastaban para explicar transformaciones sociales que demandaban políticas y prácticas educativas relacionadas con formas de organización más complejas. La toma de conciencia política en la educación dejaba en evidencia diferencias e intereses opuestos y propiciaba opciones para promover cambios estructurales. Estos a su vez requerían de actores capaces de representar los intereses de los grupos postergados, de una parte, y de estrategias políticas sobre cómo actuar frente a los poderes gubernamentales, de otra ${ }^{16}$.

También, en este contexto surgieron las críticas más serias, políticas e ideológicas a las propuestas pedagógicas y educativas de Freire, y dentro de este marco, también se generó la decisión del gobierno de la época de no renovar el contrato de consultoría internacional que mantenía con la Unesco. Al término de su gestión, Freire preparó un informe final de actividades donde da pormenorizada cuenta de lo realizado en el transcurso de los años de permanencia en el Icira. Varios de estos antecedentes se retoman en el libro autobiográfico Pedagogía de la esperanza. Un reencuentro con la pedagogía del oprimido (1992), donde Freire recuerda su trabajo con colaboradores chilenos, reflexiona sobre el clima político e intelectual que se vivía en esa época y ahonda en temas de la contingencia política y de los contextos en que se desarrolló su práctica en Brasil, primero, y en Chile, después. En Brasil, vinculado a los movimientos de cultura popular y las políticas desarrollistas de finales de los años cincuenta, y a mediados de los sesenta en Chile, como asesor, pensador e innovador político y pedagógico desde 1965 hasta su partida en $1969^{17}$.

\section{De la pedagogía política a las políticas pedagógicas (1980-1990)}

Actualmente las ideas de Freire continúan vigentes entre colectivos de educación de adultos y educación popular. También son objeto de estudio entre académicos e investigadores que examinan las relaciones entre pedagogía crítica y transformación social así como la forma en que la primera puede contribuir a una mejor comprensión de las relaciones que existen

16 En sus primeras palabras de la edición publicada en español por la editorial Tierra Nueva, en Uruguay, Freire explicaba que lo que proponía como una introducción a la pedagogía del oprimido era el resultado de observaciones en sus tres años de exilio. Observaciones a las que se sumaban las que hiciera en Brasil, en los varios sectores en que tuvo oportunidad de desarrollar actividades educativas (Freire, 1970).

17 Freire (citado por Gajardo, 2019) rinde cuentas de sus actividades al Jefe de la División de Alfabetización de Adultos de la Unesco y a las Jefaturas Nacionales en Icira, Chile. entre pedagogía y política. Tanto como la manera en que las ideas y propuestas metodológicas de Paulo Freire promueven sociedades más equitativas y permiten formular políticas para un desarrollo sostenible, poniendo el aprendizaje social y la educación de adultos al servicio del fortalecimiento de una ciudadanía activa en la vida cívica y comunitaria.

Pero Freire destaca, sobre todo, por sus propuestas metodológicas. Estas introducen elementos tremendamente innovadores en la manera de pensar y hacer educación a partir de las necesidades que imponen las condiciones de vida y de trabajo de jóvenes y adultos sin escolaridad. Entre sus aportes está el reconocer que los adultos analfabetos son poseedores de un saber y una cultura propia, que pueden y deben ser consideradas como punto de partida en los procesos de enseñanza y en la organización de los aprendizajes. Introdujo la investigación temática como etapa previa a la elaboración de contenidos educativos y trajo a la educación elementos de otras disciplinas, ampliando, con ello, el horizonte de los educadores. Utilizó enfoques y técnicas participativas de investigación social demostrando a los educadores que, a través de su práctica, podían no solo comunicar conocimientos, sino producirlos en conjunto con los educandos, y así dar un vuelco en las relaciones pedagógicas y aportar a una redefinición de los procesos del aprendizaje. Por último, aunque no por ello menos importante, Freire también destaca por su capacidad para recrear su propio pensamiento. De hecho, desde finales de los años sesenta hasta sus últimos días no dejó de reinventarse ni de expresar públicamente sus desaciertos y errores.

Aun cuando en América Latina su legado considera elementos de dulce y de agraz, es posible afirmar que todo lo que Freire realizó en Chile, antes de convertirse en un educador universal, incidió profundamente en las agendas globales que se ubican en la perspectiva de aportar a la formulación y el perfeccionamiento de políticas educativas para hacer de la pedagogía y los aprendizajes un asunto social y políticamente relevante en, al menos, cinco campos disciplinarios donde sus teorías pedagógicas se desarrollaron globalmente.

- Renovación pedagógica y aprendizaje social. Postula que enseñar no es solo transmitir conocimientos sino crear condiciones para producirlos a partir de situaciones de la vida cotidiana, sociales, políticas, económicas y culturales; que es posible experimentar con metodologías participativas donde existen actores, con distintos roles, capaces de definir rutas de aprendizaje y cursos de investigación, y que el conocimiento empírico, práctico, de sentido común de las audiencias con las que se trabaja, permite 
rescatar elementos y saberes de las culturas subalternas para utilizarlas como material de análisis social y desarrollo educativo.

- Investigaciones al servicio de los aprendizajes. Tendencia que puede encontrarse en muchas de las políticas públicas de mejoramiento educativo y en la pedagogía de movimientos y organizaciones que trabajan con el objetivo de democratizar la sociedad e incidir en las agendas contemporáneas del desarrollo, a partir de marcos conceptuales que incluyen el derecho a una educación de calidad para todos, la equidad en la distribución de las oportunidades educativas, así como la pertinencia de la educación y la enseñanza con los requerimientos del entorno, el trabajo y la participación ciudadana.

- Contribución teórica a la pedagogía critica. Las ideas pedagógicas de Paulo Freire también siguen vigentes en corrientes filosóficas y movimientos pedagógicos contemporáneos, que sustentan su práctica en el fortalecimiento de estilos de enseñanza que aportan al desarrollo de capacidades analíticas y habilidades de pensamiento crítico; se adentran en los significados y el análisis de relaciones de poder y sus consecuencias, e influyen en la agenda contemporánea del desarrollo educativo.

- Contribución al desarrollo de estilos participativos de investigación social y educativa. Especialmente aquellos que, en América Latina, se tradujeron en nuevas estrategias de investigación-acción e investigación participativa. Se trata, en general, de enfoques que sitúan la producción y comunicación de conocimientos en una misma línea de objetivos y apuntan a una comprensión global de realidades vividas por sectores social y políticamente vulnerables, así como a un análisis objetivo de obstáculos estructurales que inciden en tales situaciones. En este marco, cuatro vertientes se reconocen abiertamente como depositarias del legado que Freire hizo a los estilos participación de investigación social y educativa: a) el de las investigaciones temáticas, b) la investigación en la acción, c) la investigación participativa y d) la investigación militante. Cada una con sus propios fundamentos y marcos interpretativos que han sido ampliamente divulgados y estudiados, dentro y fuera de los países latinoamericanos.

- Aporte conceptual al campo de la teología de la liberación. Tendencia que cobró fuerza especial en algunos países de América Latina, principal- mente a través de los movimientos cristianos liderados por católicos progresistas y cristianos afines a procesos de cambio estructural. En el campo educativo, tuvo su punto más alto en los acuerdos que, sobre las relaciones entre educación y sociedad, adoptó la Comisión Episcopal Latinoamericana, entidad que reunía altas autoridades eclesiales, laicos, expertos internacionales, representantes de la Confederación Interamericana de Educación Católica, la Organización de Universidades Católicas de América Latina y la Confederación Latinoamericana de Religiosos para dar seguimiento y continuidad a las políticas emanadas de las Conferencias Generales, en especial la que se realizara en Medellín, Colombia (1968), recomendando abrir paso a la idea de una educación liberadora.

- Contribución a la construcción de identidades nacionales en países de África. Una dimensión menos conocida sobre la incidencia de las ideas pedagógicas de Freire ocurrió mientras vivía parte de su exilio en Ginebra (Suiza). Su teoría y su práctica incidieron en algunos países de África que, en los años ochenta, iniciaban procesos de descolonización y liberación nacional. Entre ellos, Guinea-Bissau que, poco tiempo después de lograda su independencia, invitó a la Unidad de Educación del Consejo Mundial de Iglesias y al Instituto de Acción Cultural (IDAC) a asesorar el diseño e implementación de un Plan Nacional de Alfabetización, formular directrices para orientar las políticas educativas de la recientemente independizada nación africana, y aportar a la formación de equipos técnicos y cuadros políticos para dirigir procesos de reconstrucción nacional, donde la educación y la enseñanza entraban como piedra angular del desarrollo.

\section{Conclusión}

Freire dejó como legado lecciones aprendidas a lo largo de tres décadas de transformaciones políticas y educativas que decantaron en nuevas formas de enseñar y aprender. Entre sus aciertos destaca su enfoque educativo que incidió fuertemente en la forma de hacer y pensar la educación de poblaciones social y políticamente vulnerables. Incidió, también, en la renovación de métodos pedagógicos en las prácticas de educación, formal y no formal.

También, destaca su capacidad de innovación metodológica. Freire consiguió imponer con sus métodos un tipo de relaciones pedagógicas distintas de las tradicionales y fomentar la participación de los actores en la gestión y desarrollo de los procesos 
educativos. Además, fue capaz de dar un giro a sus prácticas a partir de su experiencia internacional, ejercitando la autocrítica desde el momento en que se publicaron sus primeros escritos en Chile, hasta el cuándo reconoció su preocupación por lo que denominaba la mitificación de la concientización y los resultados, a veces frustrantes, de algunas prácticas con el método que, o no evaluaron los riesgos, o se dieron al margen de estrategias políticas que aseguraran una adecuada canalización del potencial de cambio generado a partir del análisis de situaciones sociales y políticas.

Finalmente, para quienes tuvieron el privilegio de colaborar con Paulo Freire en Chile queda como legado el recuerdo de su inmensa humanidad. Los testimonios hablan de la humildad con que aceptaba nuevos desafíos, de su compromiso como pensador humanista y militante, de su apertura para asumir como uno más en los equipos de trabajo, la dignidad con que llevaba el peso del exilio y su tremenda capacidad para abrir espacios de diálogo y aprendizaje que permitían conocer mejor a la persona que habitaba detrás del personaje.

\section{Referencias}

Ferreira, M. E. y Fiori, J. L. (1971). Investigación de la temática cultural de los campesinos de El Recurso. Icira, Santiago, Chile. PDF DIBAM, Santiago, Chile.

Freire, P. (1965). Educación como práctica de la libertad. Instituto de Capacitación e Inversión de la Reforma Agraria (Icira).

Freire, P. (1968). La alfabetización de adultos. Crítica de su visión ingenua; comprensión de su visión crítica. Mimeo. Santiago de Chile: Icira. www.academia.edu
Freire, P. (1970). Pedagogía del oprimido. Tierra Nueva.

Freire, P. (1971). On Cultural Action for Freedom. Harvard Educational Review, XL(1) (Monograph Series), mayo y agosto. Harvard Educational Review and Center for the Study of Development and Social Change.

Freire, P. (1972). Sobre la acción cultural. Icira, Santiago de Chile. www.academia.edu

Freire, P. (1979). Acao cultural para a liberdade e outros escritos. Paz e Terra Ed.

Freire, P. (1985). Cartas a Guinea-Bissau. México: Siglo XXI Editores.

Freire, P. (1992). Pedagogía de la esperanza: un reencuentro con la pedagogía del oprimido. México: Siglo XXI Editores.

Freire, P. y Guimarães, S. (1985). Aprendendo com a propia historia. Paz e Terra Editores.

Gajardo, M. (2019). Paulo Freire. Crónica de sus años en Chile. Flacso.

Gadotti, M. et al. (1996). Paulo Freire. Una biobibliografía. Cortez Editora, Unesco, Instituto Paulo Freire.

Inodep (1972). El mensaje de Paulo Freire. Teoría y Práctica de la Liberación. Editorial Marsiega.

Ministerio de Educación de Chile (Mineduc) (1966a). La educación de adultos en Chile. Santiago de Chile.

Ministerio de Educación de Chile (Mineduc) (1966b). Manual del método psico-social para la enseñanza de adultos. Ed. Santillana.

Torres, C. A. (comp.). (1979). Entrevistas con Paulo Freire. Ediciones Gernika. 